\title{
Race-Based Medicine: An Unscientific Proxy That Persists Racial Bias
}

RODRIGO PEREZ-MAGNELLI (D)

*Author affiliations can be found in the back matter of this article

\section{ABSTRACT}

Systems of racial classification have inherent incoherencies which have caused a misconstrued concept of race that requires amelioration in present-day society and medicine. Races like White and Black incorrectly generalize people based on arbitrary criteria that inevitably result in racial bias. Biological differences between people of different races do exist, however these differences do not constitute race per se, but localized interbreeding over time between people of a geographic location leading to traits becoming predominant in those respective populations. That is, biological differences arise due to evolutionary genetics, not inherent categories of mankind. Characteristics like skin color and hair texture are no more meaningful than other features that vary among human appearance, such as hair color, eye color, and height, since genetic difference is found in most biological aspects of the body with no regard to the arbitrary physiognomic and other visual differences that human culture perceives. The societal construction of race becomes further evident when evaluated for the mixing of races in which racial categories effectively dissolve. All humans correspond to the same species and share all the physiology and genetics that make us human. Fine-scale genetic variation of about $0.1 \%$ exists between populations and individuals, but society picks and chooses the phenotypes that it wishes to portray as distinctive groups of people.

Medicine should include the genetics of difference when making clinical decisions without mistakenly reinforcing race due to its stigmatizing, prejudicing connotations and persistence of harmful racial bias. Many claimed racial biological differences, such as hypertension in African-Americans, are attributed more so to environmental conditions than to genetic factors. Medical differences can arise from inherited deleterious mutations of ancestral origin that were retained in certain areas and populations due to persistent, relatively isolated breeding. But to simply attribute observed differences in health to mere racial categories despite the biological inconsistency of race is to deny patients of their individuality and right to beneficence and justice. Instead, racebased medicine must be salvaged for more scientific practices that do not presuppose unethical racial difference but examine genetic difference in patients as individuals to alleviate racial health disparities.
CORRESPONDING AUTHOR:

\section{Rodrigo Perez-Magnelli}

University of Missouri - Kansas City School of Medicine, US rperez-magnelli@ail.umkc. edu

\section{KEYWORDS:}

Race-Based Medicine; Genetics of Race; Genetics of Difference

TO CITE THIS ARTICLE: Perez-Magnelli R. Race-Based Medicine: An Unscientific Proxy That Persists Racial Bias. ISMMS Journal of Science and Medicine. 2021; 1(1): 13, pp. 1-2. DOI: https://doi. org/10.29024/ijsm.33 
The author has no competing interests to declare.

\section{AUTHOR AFFILIATION}

Rodrigo Perez-Magnelli (D) orcid.org/0000-0002-9943-230X

University of Missouri - Kansas City School of Medicine, US and Medicine. 2021; 1(1):

13, pp. 1-2. DOI: https://doi. org/10.29024/ijsm.33

Submitted: 15 December 2020 Accepted: 15 December 2020 Published: 27 January 2021

COPYRIGHT:

(c) 2021 The Author(s). This is an open-access article distributed under the terms of the Creative Commons Attribution 4.0 International License (CC-BY 4.0), which permits unrestricted use, distribution, and reproduction in any medium, provided the original author and source are credited. See http://creativecommons.org/ licenses/by/4.0\%.

ISMMS Journal of Science and Medicine is a peer-reviewed open access journal published by Levy Library Press. 